Original Research Article

\title{
A study on drug utilization pattern of antihypertensive drugs in hypertensive diabetic patients
}

\author{
Vikash Verma ${ }^{1}$, Mukesh Kumar ${ }^{1 *}$, Arvind Gupta ${ }^{1}$, Kavita Dhar ${ }^{2}$, Jyotshana Sharma ${ }^{2}$
}

${ }^{1}$ Department of Pharmacology, G.S. Medical College and Hospital, Pilkhuwa, Hapur, Uttar Pradesh, India

${ }^{2}$ Department of Pharmacology, Santosh Medical College, Ghaziabad, Uttar Pradesh, India

Received: 06 July 2019

Revised: 13 August 2019

Accepted: 11 September 2019

*Correspondence to:

Dr. Mukesh Kumar,

Email: mukeshkumar4074

@ gmail.com

Copyright: (C) the author(s), publisher and licensee Medip Academy. This is an openaccess article distributed under the terms of the Creative Commons Attribution NonCommercial License, which permits unrestricted noncommercial use, distribution, and reproduction in any medium, provided the original work is properly cited.

\begin{abstract}
Background: Hypertension management is of paramount importance in diabetic patients for reduction of cardiovascular and other complications. The objective of the present study was to assess prescribing pattern of antihypertensive drugs in hypertensive type 2 diabetic patients and evaluate them by comparing with Eighth Joint National Committee (JNC-8) hypertension treatment guidelines.

Methods: A prospective observational study was carried out on 110 hypertensive type 2 diabetic patients of age 41-80 years visiting outpatient department of Medicine at G.S. Medical College and Hospital, UP, India for 4 months. JNC-8 hypertension management guideline was considered while evaluating the prescribed drugs. All the relevant data was collected from the prescription card of the patient on a preformed performa and analyzed using descriptive statistics.

Results: Total of 176 drugs was prescribed to the study patients among which two drug combination therapy $(55.45 \%)$ was mostly used. The most common group prescribed was angiotensin receptor blocker (ARB) (29.45\%) and $\mathrm{ARB}+\mathrm{CCB}$ (calcium channel blockers) $(34.92 \%)$ were the commonest fixed drug combination. Overall, it was amlodipine $(21.47 \%)$ that was most frequently prescribed among all antihypertensive drugs.

Conclusions: ARB was the most commonest class, $\mathrm{ARB}+\mathrm{CCB}$ was the most frequent fixed drug combination prescribed to the study patient while amlodipine was the highly utilized individual antihypertensive drug in the study. Prescriptions evaluation revealed that $94.88 \%$ prescription were rational and were in accordance with the JNC- 8 hypertension treatment guidelines except the use of beta blockers $(5.12 \%)$.
\end{abstract}

Keywords: Hypertension, Type 2 diabetes mellitus, Antihypertensive drugs, Amlodipine, Telmisartan

\section{INTRODUCTION}

Diabetes mellitus and hypertension are interrelated diseases that strongly predispose an individual to atherosclerotic cardiovascular complications. ${ }^{1}$ The incidence of hypertension in patients with type 2 diabetes mellitus is approximately two-fold higher than in agematched subjects without the disease. ${ }^{2}$ The prevalence of hypertension coexisting with diabetes appears to be increasing mainly in ageing population as both hypertension and non-insulin dependent diabetes mellitus incidence increases with age. ${ }^{3}$ Hypertension has been identified as a major risk factor not only for the development of diabetes but also for the development of micro and macro vascular complications, that is, neuropathy, nephropathy, retinopathy, coronary artery disease, stroke, peripheral vascular disease in diabetic patients. $^{4,5}$

Reduction in either isolated systolic or systolic-diastolic hypertension significantly reduces the risk of micro and macro vascular complications and cardiovascular death or diabetes-related death. ${ }^{6,7}$ The Eighth Joint National Committee i.e., JNC-8 (Table 1) guidelines recommends that blood pressure (BP) in diabetics be controlled to levels of $140 / 90 \mathrm{mmHg}$ or lower. ${ }^{8,9}$ Whatever the goal level, optimal control of BP is paramount for reducing the 
progression of diabetic nephropathy to end stage renal disease and other complications. ${ }^{10}$

Effective management and treatment for hypertension needs proper screening and diagnosis. Treatment includes both non-pharmacologic (lifestyle changes, dietary changes) and pharmacological i.e., medication therapy to lower blood pressure and prevent cardiovascular events such as a heart attack, stroke. There are many classes of anti-hypertensives, which lower blood pressure by different means. Non-pharmacological interventions should be used throughout the management of all patients with high blood pressure. ${ }^{11,12}$

Given the importance of the blood pressure control in diabetic patients, there has been much needed data on achievement of target control in real world diabetic hypertensive patients. This study was conducted with the objective of assessing the prescribing pattern of antihypertensive drugs in hypertensive diabetic patients in clinical settings. Further, the study also assessed adherence of prescribing pattern with JNC-8 hypertension management guidelines.

\section{METHODS}

A prospective observational study was carried out on 110 hypertensive type 2 diabetic patients visiting the outpatient department of Medicine of G. S. Medical College and Hospital, Hapur, UP, India from Febrauary 2019 to May 2019 for a duration of 4 months.

\section{Procedure}

Antihypertensive drugs prescribed by the physician to the study patient were noted down mentioning the class, dose, frequency and duration from the patient's prescription card in a preformed performa. Beside the antihypertensive drugs, the demographic information and preliminary medical history (present complain, smoking, alcoholism, presence of other disease, drug history, family history of disease) was also inquired with them directly and noted. BP reading was recorded by using sphygnomanometer keeping the patient in sitting position and JNC-8 hypertension management guideline.

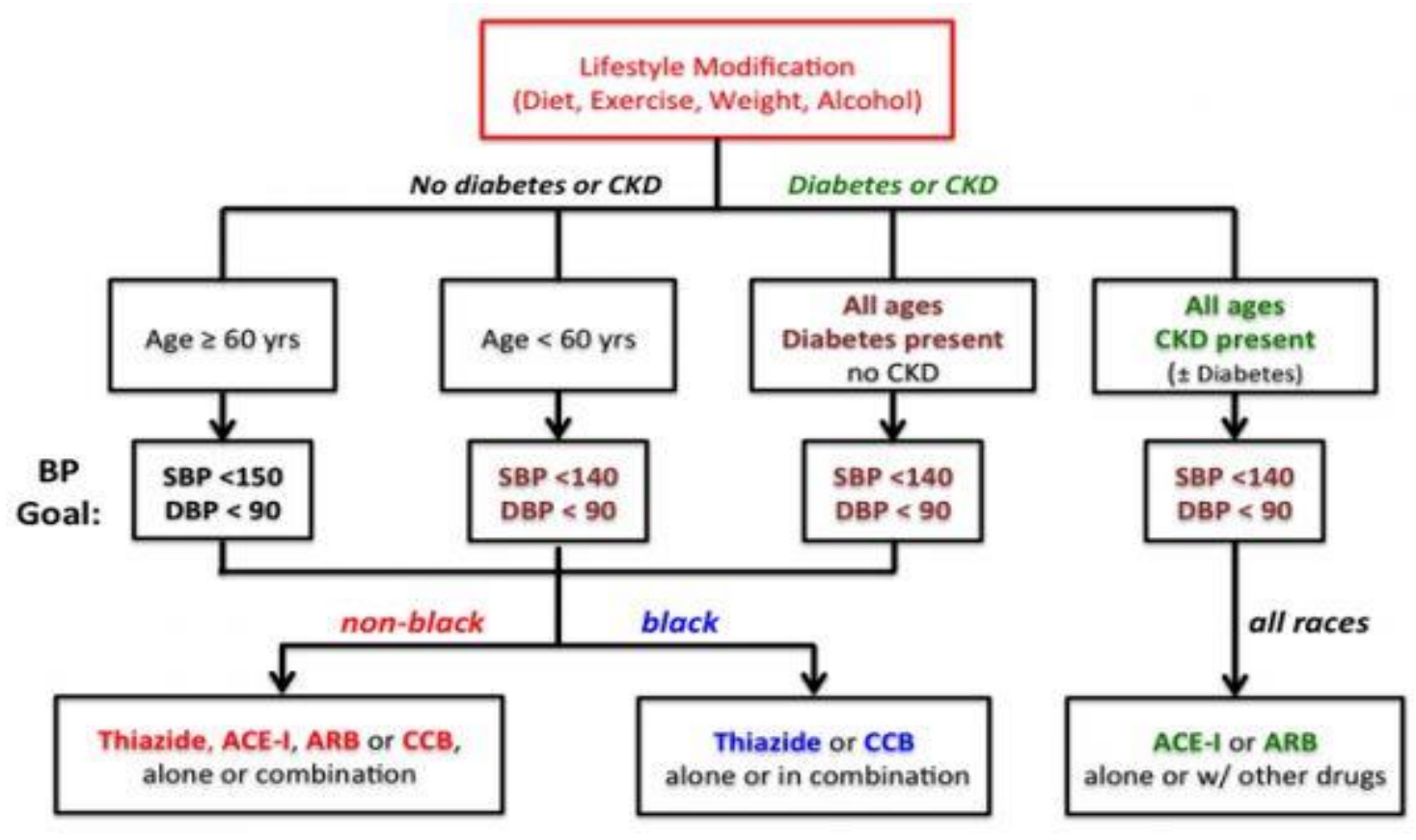

Adapted from: James et al, JAMA 311(5):507-20, 2014

Figure 1: JNC-8 hypertension treatment guidelines.

Figure 1 was considered while evaluating the prescribed drugs. Hypertensive diabetic patient of age 41-80 years of either sex were included in the study whereas pregnant woman and study patients suffering from comorbities other than diabetes were excluded. Patient treated for hypertensive urgency and emergency were also excluded from the study.

\section{Inclusion criteria}

Hypertensive type 2 diabetic patient of both gender, hypertensive type 2 diabetic patients of age between 41 80 years and hypertensive type 2 diabetic patients receiving drugs for both hypertension and diabetes during the study period. 


\section{Exclusion criteria}

Patients treated for hypertensive urgency and emergency, pregnant woman suffering from hypertension and diabetes and hypertensive diabetic patient suffering from other co-morbidities.

All the patients were clearly explained about the nature of the study and their written consent was taken. Study was carried out after obtaining ethical certificate from Institutional ethical committee of G. S. Medical College and Hospital.

\section{Statistical analysis and data assessment}

The data obtained from the observation was categorized and tabulated in terms of number and percentage on Microsoft Excel worksheet. Analysis was performed using International business machine with statistical package for the social sciences (IBM-SPSS) version 21. The final results achieved were analysed using descriptive statistics and graphically presented via bar chart, column chat and pie chart wherever necessary.

\section{RESULTS}

Out of 110 study patients, males $(58.18 \%)$ were higher than their female participants (41.82\%). While evaluating the study patients as per their age group, it was found that patients between ages 71-80 years were highest (46\%) followed by 61-80 years (Figure 2).

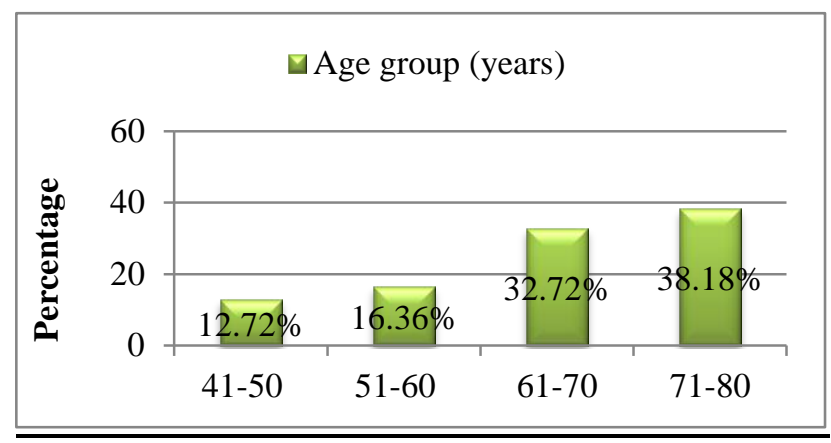

Figure 2: Percentage distribution of study patients as per their age group.

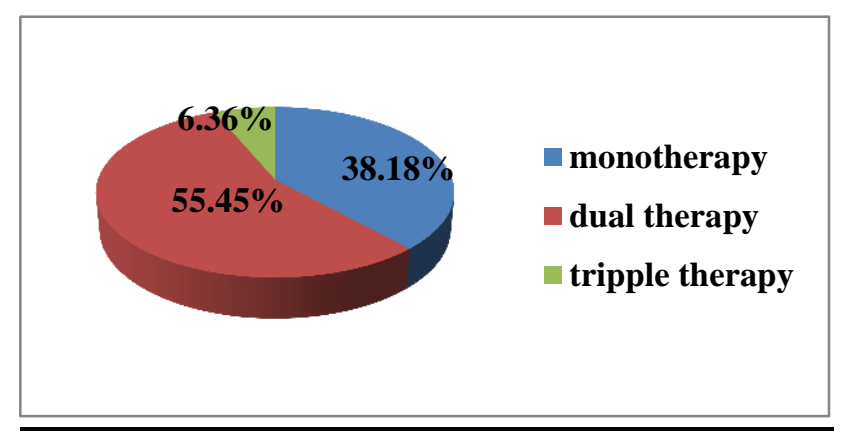

Figure 3: Percentage distribution of study patients as per the no. of drugs prescribed.
In the present study of 110 patients, two drug therapy $(55.45 \%)$ was utilized the most to treat the study participants followed by mono-therapy (38.18\%) and triple drug therapy (Figure 3). All the drugs used under two drug therapies were in form of fixed drug combinations only.

In the current study, total of 176 drugs were prescribed to the study population among which angiotensin receptor blocker (ARB) (29.54\%) were the most frequently prescribed drug class followed by calcium channel blockers (CCB) $(24.43 \%)$ while beta blockers $(5.12 \%)$ were the least prescribed (Table 1).

Table 1: Distribution of antihypertensive drugs prescribed to the study patients.

\begin{tabular}{|llll|}
\hline S. no. & Drug class & $\mathbf{n = 1 7 6}$ & \% \\
\hline $\mathbf{1}$ & ACEI & 40 & 22.72 \\
\hline $\mathbf{2}$ & ARB & 52 & 29.54 \\
\hline $\mathbf{3}$ & CCB & 43 & 24.43 \\
\hline $\mathbf{4}$ & Thiazide diuretic & 32 & 18.18 \\
\hline $\mathbf{5}$ & Beta blockers & 9 & 5.12 \\
\hline
\end{tabular}

In the given study, it was found that total of 71 fixed drug drugs combinations were used among which $\mathrm{ARB}+\mathrm{CCB}$ $(33.80 \%)$ was utilized the most followed by ACEI+thiazide diurectic $(23.94 \%)$ and others (Table 2). It was also observed that beta blockers were not present in any of the fixed drug combinations.

Table 2: Distribution of fixed drug combinations prescribed to the study patients.

\begin{tabular}{|ll|ll|}
\hline $\begin{array}{l}\text { Sr. } \\
\text { No. }\end{array}$ & Fixed drug combination & $\mathbf{n}=71$ & $\%$ \\
\hline $\mathbf{1}$ & ARB+CCB & 24 & 33.80 \\
\hline $\mathbf{2}$ & ACEI+THZD & 17 & 23.94 \\
\hline $\mathbf{3}$ & ARB+THZD & 14 & 19.71 \\
\hline $\mathbf{4}$ & ACEI+CCB & 16 & 22.53 \\
\hline
\end{tabular}

ACEI: Angiotensin converting enzyme inhibitors, ARB: Angiotensin receptor blocker, CCB: Calcium channel blocker, THZD: Thiazide diuretic.

Table 3: Distribution of individual antihypertensive drugs prescribed to the study patients.

\begin{tabular}{|llll|}
\hline S. no. & Drug & $\mathbf{n = 1 7 6}$ & \% \\
\hline $\mathbf{1}$ & Ramipril & 14 & 7.95 \\
\hline $\mathbf{2}$ & Enalapril & 19 & 10.80 \\
\hline $\mathbf{3}$ & Captopril & 7 & 3.97 \\
\hline $\mathbf{4}$ & Amlodipine & 36 & 20.45 \\
\hline $\mathbf{5}$ & Nifidipine & 7 & 3.97 \\
\hline $\mathbf{6}$ & Telmisartan & 26 & 14.77 \\
\hline $\mathbf{7}$ & Candesartan & 10 & 5.68 \\
\hline $\mathbf{8}$ & Losartan & 16 & 9.90 \\
\hline $\mathbf{9}$ & Hydrochlorothiazide & 32 & 18.18 \\
\hline $\mathbf{1 0}$ & Atenolol & 6 & 3.40 \\
\hline $\mathbf{1 1}$ & Carvedilol & 3 & 1.70 \\
\hline
\end{tabular}


While analyzing the individual antihypertensive drugs in the current study, it was found that amlodipine $(20.45 \%)$ was the most frequently prescribed antihypertensive drug to the study participants followed by hydrochlorothiazide $(18.18 \%)$ while carvedilol $(1.70 \%)$ was the least prescribed drug (Table 3).

\section{DISCUSSION}

The present study found male (58.18\%) to be significantly higher than female patients. The possible reason of male dominance in our study might be because of the low socio-economic status of female in this geographical area thus having relatively less exposure to medical visits. While evaluating the age group of study patients, it was found that the maximum no of patients were between the age of $71-80$ years $(38.18 \%)$ followed by $61-70$ years $(32.72 \%)$ while the patients of age group between $41-50(5.5 \%)$ were least in number. The result of our study is supported by a study carried out by Feskens et al which states the increasing age is a risk factor for CVS disease and diabetes. ${ }^{13}$ Two drug combinations $(55.45 \%)$ in the form of fixed drug combination, was utilized the most in our study followed by monotherapy $(38.18 \%)$ and three drug combinations. This is in alignment with the idea that most diabetic patients with hypertension needs minimum of two drugs to control their blood pressure within the optimal range. ${ }^{14}$

It was observed that angiotensin receptor blocker (29.54\%) were the most frequently used drug class to treat the study participants followed by calcium channel blocker $(24.43 \%)$. Our study is supported by another similar study carried out by Khrime et al in 2014 at Shri Guru Ram Rai Institute of Medical and Health Sciences, Dehradun where they also concluded angiotensin receptor blocker $(44.39 \%)$ to be the highest prescribed drug class. ${ }^{15}$ But, when Song et al carried out a similar study at Zhejiang university, China, they found calcium channel blocker $(58.47 \%)$ to be the most utilized drug class. ${ }^{16}$ However, use of both calcium channel blockers or angiotensin receptor blocker is justified in hypertensive diabetic patients as per JNC-8. ${ }^{17}$

The present study found that total of 71 fixed drug combination were used among which $\mathrm{ARB}+\mathrm{CCB}$ $(33.80 \%)$ was the most commonest succeeded by ACEI+thiazide $(23.94 \%)$ which is in agreement with the guidelines laid down by $\mathrm{JNC}-8 .{ }^{17}$ Use of fixed drug combinations in treatment of hypertension is justified by a fact that FDC generally increases the effectiveness by targeting two different mechanism, improves compliance and decreases side effects by counteracting the unwanted effects produced by the other drug present in the combination. ${ }^{18}$

While analyzing the individual antihypertensive drug in the current study, it was found that amlodipine (20.45\%) was the most prescribed drug to the study patient both in monotherapy and combination therapy followed by hydrochlorothiazide (18.18\%). Alavuddin et al carried a similar study in hypertensive diabetic patient in 2015 in Saudi Arabia and also found amlodipine (39.6\%) to be the most utilized drugs for treatment of the study subjects. ${ }^{19}$ Increased use of amlodipine may be related to its better clinical efficacy to control hypertension and very few contraindication associated with it.

\section{CONCLUSION}

Total of 176 drugs were used to treat the study patients among which two drug combinations was the most dominant. ARB followed by CCB was most commonly used class in the study subjects. Among all the antihypertensive drugs, amlodipine was utilized for majority of the patients, either in monotherapy or in polytherapy. Fixed drug combination of $\mathrm{ARB}+\mathrm{CCB}$ was utilized the most followed by ACEI+thiazide diuretic. On evaluation of all the prescribed drugs it was found that the entire drug prescribed were rational and were in accordance with JNC-8 treatment guidelines except the use of beta blockers which was prescribed in few patients. However, study on much larger population is required so that result can be translated for the further and more precise benefit of the medical community.

\section{ACKNOWLEDGEMENTS}

We would like to thank all the faculty and staff members of Department of Medicine for their co-operation during the study period and all the patients who participated in the study.

\section{Funding: No funding sources \\ Conflict of interest: None declared}

Ethical approval: The study was approved by the Institutional Ethics Committee

\section{REFERENCES}

1. El-Hazmi MA, Warsy AS. Association of hypertension and non-insulin-dependent diabetes mellitusin the Saudi population. Ann Saudi Med. 2001;21(1-2):5-8.

2. Kearney PM, Whelton M, Reynolds K, Muntner P, Whelton PK, He J. Global burden of hypertension: analysis of worldwide data. Lancet. 2005;365(9455):217-23

3. Venugopal K, Mohammed MZ. Prevalence of hypertension in type-2 diabetes mellitus. CHRISMED J Health Res. 2014;1(4):223-7.

4. Muntner P, Woodward M, Mann DM, Shimbo D, Michos ED, Blumenthal RS, et al. Comparison of the framingham heart study hypertension model with blood pressure alone in the prediction of risk of hypertension: the multi-ethnic study of atherosclerosis. Hypertens. 2010;55(6):1339-45.

5. Emdin CA, Rahimi K, Neal B, Callender T, Percovic $\mathrm{V}$, PatelA. Blood pressure lowering in type 2 
diabetes: a systematic review and meta-analysis. JAMA. 2015;313:603-15.

6. Fuller J, Stevens LK, Chaturvedi N, Holloway JF. Antihypertensive therapy for preventing cardiovascular complications in people with diabetes mellitus. Cochrane Database of Systematic Reviews. 2000;2:CD002188.

7. Bakris GL, Williams M, Dworkin L, Elliott WJ, Epstein M, Toto R, et al. Preserving renal function in adults with hypertension and diabetes: a consensus approach. Am J Kidney Dis. 2000;36(3):646-61.

8. Paul JA, Suzzane O, Carter BL, Cushman WC, Himmelfarb CD, Handler J, et al. Evidence-based guideline for the management of high blood pressure in adults: report from the panel members appointed to the Eighth Joint National Committee (JNC 8). JAMA. 2014;311(5):507-20.

9. Kjeldsen S, Feldman RD, Lisheng L, Mourad JJ, Chiang CE, Zhang W, et al. Updated national and international hypertension guidelines. Drugs. 2014;74(17):2033-51.

10. Shah J, Khakhkhar T, Bhirud S, Shah RB, Date S. Study of utilization pattern of anti-hypertensive drugs in hypertensive diabetic patients with or without reduced renal function at tertiary care teaching hospital. Int J Med Sci Public Health. 2013;2(2):17580 .

11. Anthony V. Screening for hypertension and lowering blood pressure for prevention of cardiovascular disease events. Med Clin North Am. 2017;101(4):701-12.
12. Mark N. Drug treatment of elevated blood Pressure. Aust Presr. 2010;33:108-12.

13. Feskens EJ, Kromhout D. Cardiovascular risk factors and the 25-year incidence of diabetes mellitus in middle-aged men. Am J Epidemiol. 1989;130(6):1101-8.

14. García CG, Guerra AFR. Combination therapy in the treatment of hypertension. Drugs Context. 2018;7:212531.

15. Khrime D, Kumar A, Pandey AN, Bansal N, Sharma U, Varma A. Antihypertensive drug utilization pattern and awareness in diabetic hypertensive patients at tertiary care centre. Int J Res Med Sci. 2015;3(5):461-5.

16. Song L, Fang LZ, Chen JH. Utilization pattern of antihypertensive drugs in Chinese diabetics. Biomed Res. 2017;28(1):178-84.

17. Vila EH. A review of JNC-8 Blood pressure guidelines. Texas Heart Institute J. 2015;42(3):226-8.

18. Sica DA. Rationale for fixed drug combination for treatment of hypertension: the cycle repeats. Drugs. 2002;62(3):443-62.

19. Alavudeen SS, Alakhali KA, Ansari SMA, Abdulla N. Prescribing pattern of antihypertensive drugs in diabetic patients of Southern Province, Kingdom of Saudi Arabia. Ars Pharm. 2015;56(2):109-14.

Cite this article as: Verma V, Kumar M, Gupta A, Dhar K, Sharma J. A study on drug utilization pattern of antihypertensive drugs in hypertensive diabetic patients. Int J Basic Clin Pharmacol 2019;8:2242-6. 